\title{
The Study on Estimating the Scale of Local Government Debt in China*
}

\author{
Han Ying, Shi Jianhua, Yan Yadong, Wu Xingnan \\ Institute of Business Administration Northeastern University, Shenyang 110006, China \\ Hanying@hanying139@163.com
}

\begin{abstract}
Whether at home or abroad, local debts play an important role in easing the contradiction between supply and demand of funds, and promoting local economic development and other aspects. The measure of the appropriate local debts scale is the basis to control local debts risks, and it is an important issue in the study of local debts. Based on the analysis on the influence factors of local debts scale, we build a panel data model of moderate local debts scale, calculate 30 provinces and cities where local debts are issued by the moderate scale, and provide basic methods for the issuance scale of local debts.
\end{abstract}

Index Terms - local debts, appropriate scale, panel data model

Local government bonds(hereinafter called local debts) is mainly refer to a financing form of raising funds, which makes the local government uses credit tool in order to meet the needs of the development of the local economic and social public welfare under the shortage of regular revenues, in accordance with the relevant legal provisions. At present, 37 countries allow to issue local debts of 53 major countries in the world.

China's local debts is a very tortuous course. The future of local debts will be according to the following pattern transformation, namely "central government on behalf $\rightarrow$ self-issuing $\rightarrow$ issuing autonomously". [1]

Only moderately issuing local debts can governments control and reduce the local debts risks and the local financial crisis from the source, so that the local debts really plays a role to promote local economic development and social stability. Determining the appropriate scale of government bonds has become an important problem to research. To measure the debt scale is the foundation of moderately issuing.

Research on government debt scale of foreign scholars: government debt issuance should control the scale[2-5]. Influence factors of the government debt issuance scale[2-5] mainly include GDP, fiscal revenue, income distribution, deposit, urbanization rate, population flow, interest rate etc.

Quantitative research methods of China's local debts issuance scale are: (1) KMV model. Scholars such as Wang Gang[6] put forward the concept of the default risk of municipal bonds on the basis of American municipal bonds, and build the credit risk model for municipal bonds by using KMV model. He calculates the debt scale of different default probability by taking Beijing and Shanghai as examples. (2) Theoretical inference. Scholars such as Wang Yu[7] conclude that: in the rational expectations equilibrium model, when the control of the government can not improve the cash flow in the future, investors will refuse to buy the bonds. Therefore, a small risk of insolvency will lead to a great risk of immobilization. (3) Regression model. Scholars such as Cheng Zhenhuang ${ }^{[8]}$ taking a county for example, assuming government debts scale as the explained variable, GDP, fiscal revenue, fiscal expenditure as the explanatory variables, analyze the influence of each explanatory variable on the county's debt, and predict the county's appropriate debt scale over the next 15 years. International alert ratio index are used to analyze the data.

In conclusion, whether using the KMV model to explore the local debt scale, or analyzing in view of local fiscal sustainability, their analyses depend on a single region (province or municipality or county), without considering the regional competition and cooperation effect and characteristics of public goods.

\section{The Construction of Scale Model}

\subsection{Determination of scale model}

\subsubsection{The factors affecting local debt scale}

Reference to relevant research results of local debt issuance, the general effect factors include: the regional gross domestic product, the local fiscal revenue, residents deposit balance, regional urbanization level and interest rate. Other factors not listed are attributed to random interference term.

It depends on different situations whether these factors in a certain period or an area really affect local debts. Therefore, concrete influence factors of local debts in different areas or with different times are distinct

\subsubsection{The variable and sample}

We regard the region's GDP, fiscal revenue, residents deposit balance, urbanization rate, benchmark one-year deposit rate as the explanatory variable. Due to the constraint of "budget law", the local debt scale has no exact statistics. According to the role of local debts which is to increase the infrastructure construction and improve the level of public services, we regard the sum of capital construction investment and renovation investment as explained variable (referred to as the local debts scale).

Because China started a proactive fiscal policy in 1998, so we select above indexes from 1998 to 2009 of China's 30 provinces, municipalities directly under the central government

"This work is partially supported by the national natural science fund project (71272163), philosophy and social science fund project in Liaoning province. 
and autonomous regions as samples, which is a total of 360 samples.

\subsubsection{The selection of scale model}

Considering that the supply of public goods will produce synergistic effect, competition effect, population flow among adjacent region, which can lead to cost sharing, benefit sharing, public services or infrastructure provided by the regional government have external effects, we sometimes need to coordinate construction of several areas. We analyze these interrelated and mutually coordinated relationship, using panel data model to determine the effect of individual influence each other on local debt issuance.

Because the local debts is mainly used for infrastructure construction, investment period is long. Taking into account that the scale of raising local debts is influenced by the issuance size of the previous period, first-lagged explained variable will be regarded as an explanatory variable. Differences between the individual members can be seen as changes in the parameters of the regression coefficients, and fixed effects model is a reasonable model of panel. We intend to establish a fixed effects model:

$$
\begin{aligned}
& \ln \left(D E_{i t}\right)=\alpha_{i}+\beta_{1} \cdot \ln \left(G D P_{i t}\right)+\beta_{2} \cdot \ln \left(F I_{i t}\right) \\
& +\beta_{3} \cdot \ln \left(U_{i t}\right)+\beta_{4} \cdot \ln \left(S_{i t}\right) \\
& +\beta_{5} \cdot \ln \left(I_{i t}\right)+\beta_{6} \cdot \ln \left(D E_{i, t-1}\right)+u_{i t} \\
& i=1,2, \cdots N, \quad t=1,2, \cdots, T
\end{aligned}
$$

In the formula (1): $D E$ is expressed as local debt scale; $G D P$ is expressed as gross domestic product; $F I$ is expressed as fiscal revenue (general budget revenue); $U$ is expressed as urbanization rate; $S$ is expressed as residents' deposit balance; $I$ is expressed as benchmark one-year deposit rate; $N=30$, $i=1,2, \cdots, N$ is expressed as different regions; $T=12$, $t=1,2, \cdots, T$ is expressed as annual sequence of the sample. $u_{i t}$ is expressed as random error term; $\alpha_{i}$ is expressed as the individual differences of cross section.

\section{2 data verification} method.

We make unit root test by using ADF panel unit root test

Under the $1 \%$ significant level, $\ln (D E), \ln (U)$ and $\ln (I)$ are $\mathrm{I}(0), \ln (G D P), \ln (F I)$ and $\ln (S)$ are $\mathrm{I}(1)$.

If using $\Delta \ln (G D P), \Delta \ln (F I)$ and $\Delta \ln (S)$ for first difference of $\ln (G D P), \ln (F I)$ and $\ln (S), \ln (D E), \Delta \ln (G D P), \Delta \ln (F I)$, $\ln (U), \Delta \ln (S)$ and $\ln (I)$ are $\mathrm{I}(0)$.

\section{3 parameter estimation}

Based on the test results, we select explained variable $\ln (D E)$, explanatory variables $\Delta \ln (G D P), \Delta \ln (F I), \ln (U), \Delta \ln (S)$ and $\ln (I)$. Then we intend to establish fixed effect model:

$$
\begin{aligned}
& \ln \left(D E_{i t}\right)= \alpha_{i}+\beta_{1} \cdot \Delta \ln \left(G D P_{i t}\right)+\beta_{2} \cdot \Delta \ln \left(F I_{i t}\right) \\
&+\beta_{3} \cdot \ln \left(U_{i t}\right)+\beta_{4} \cdot \Delta \ln \left(S_{i t}\right) \\
&+\beta_{5} \cdot \ln \left(I_{i t}\right)+\beta_{6} \cdot \ln \left(D E_{i, t-1}\right)+u_{i t} \\
& i=1,2, \cdots N, \quad t=1,2, \cdots, T, N=30, T=11 。
\end{aligned}
$$

Using the OLS method and the Eviews6.0 software, we make parameter estimating of formula (2). We get some explanatory variables which can not pass the t-test (such as interest rates). Based on this, we will combine explain variables to get 12 models, and then estimate the model parameters. 3 models pass statistical test shown in table 1 .

TABLE 1 Results That Have Passed Test

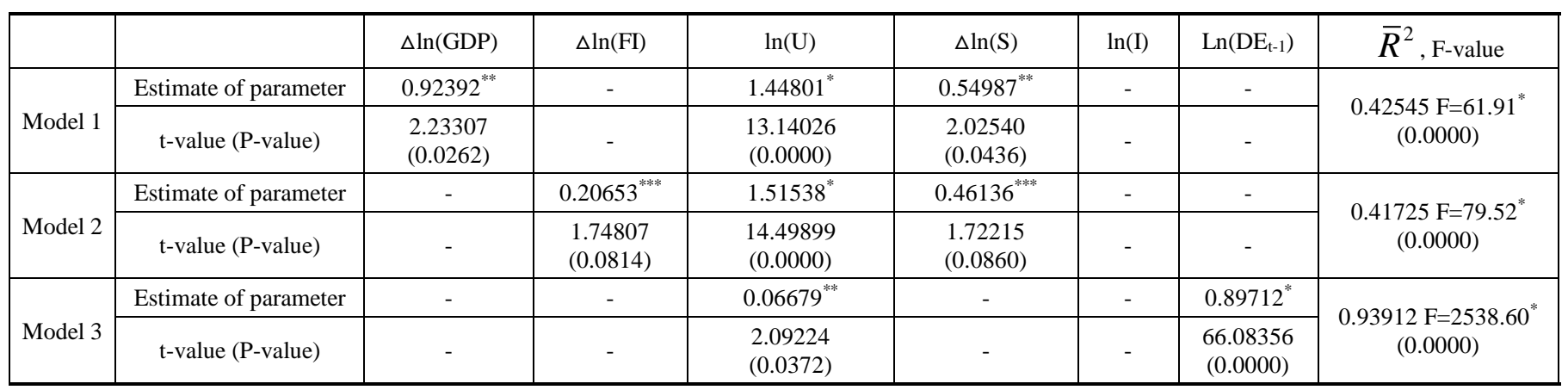

Note: $* * *, * * *$ are very prominent respectively under the confidential level of $1 \%, 5 \%$ and $10 \%$

Seen from table 1: the explanatory variables of the model under the level of $1 \%$ or $5 \%$ or $10 \%$ pass t-test, and they pass F-test under $1 \%$ level. So these three models are reliable, and can be used to estimate or forecast of local debts. Based on table 1 and the results of the above models, we can get the following conclusion: rate of interest is a small effect on the local debts. If $\Delta \ln (\mathrm{GDP})$ is expressed as explanatory variable, $\Delta \ln (\mathrm{FI})$ is also a small effect on the local debts of China. If $\operatorname{Ln}\left(\mathrm{DE}_{\mathrm{t}-1}\right)$ is expressed as explanatory variable, $\Delta \ln (\mathrm{GDP}), \Delta \ln (\mathrm{FI})$ and $\Delta \ln (S)$ are small effects on the local debts of China. 


\section{Calculation of Local Debts}

Based on the results of table 1 , we calculate the local debts from 2011 to 2012 by using 3 models respectively. The data is converted into prices of current year. The calculation results are shown in table 2(unit: a hundred million yuan)

According to formula (3), $\hat{y}$ is a combination forecast.

$$
\hat{y}=\frac{1}{3} \times \hat{y}_{1}+\frac{1}{3} \times \hat{y}_{2}+\frac{1}{3} \times \hat{y}_{3}
$$

Each estimation result in table 2 is different, but no matter in which estimation result, issuance sizes of Shanghai and Guangdong Province are relatively larger than others, because the two regions are not only relatively developed economy, but also both attract a large number of migrant workers. Because the urban population in the two is big, they need more infrastructure and other public services, and financial resources are not able to make up the gap, and thus more local debts is required.

TABLE 2 The results of local debts during 2011 to 2012 in China

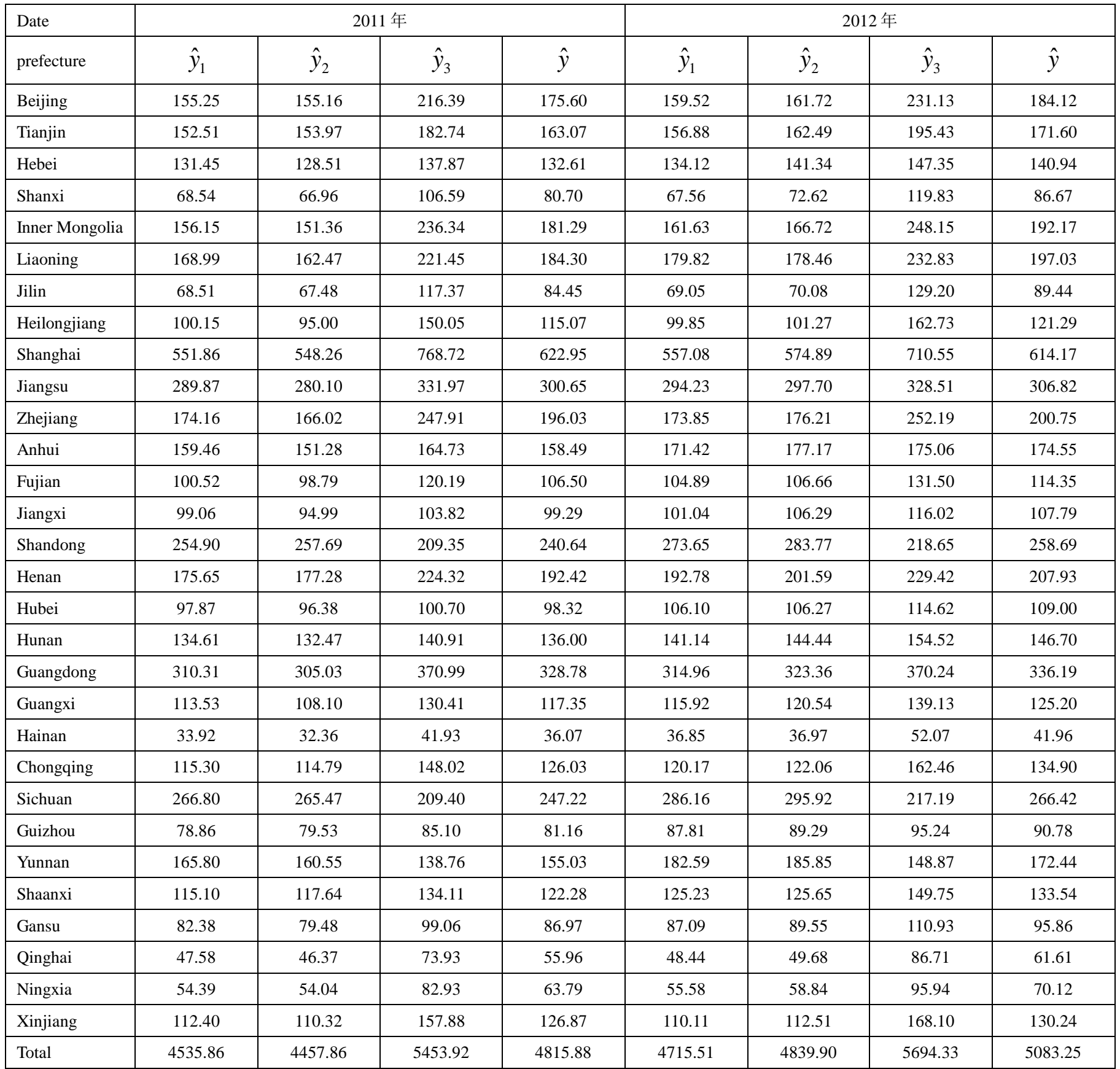


It should be noted that, it is not comprehensive that local government chooses the local debt scale only according to the results of table 2 . We also need to use proportion method to control the risk of local debts, such as the local debt borrowing rate controlled at less than $10 \%$, dependence degree of debt less than $15 \%$, and the debt service ratio less than $8 \%$, in order to guarantee the local debt repayment and local government credit. In addition, the country's macroeconomic policies affect the circulation of local debts. Local government needs to consider various factors to select the issuance size.

To conclude, early in the issuance of local debts, the local government must choose the issuance carefully.

\section{Epilogue}

Perfecting the system of tax distribution, promoting local economic development and pushing deep reform of market economy require autonomous local debts. But it does not mean local government can issue local debts without limit. Local government must control its overall size to avoid the risk caused by the size of the debt out of control and the risk may be transmitted to the central level, affecting the entire country's macroeconomic stability.

The scale risk of the local debts is the most direct risk. It is very important for the issuance, underwriting and transaction of the local debts, because it will affect people's willingness to buy and local debt liquidity. Local debts issuance needs comprehensive consideration of economic development level, government's fiscal revenue, ability of money supply inside and outside the jurisdiction, urbanization level and quality and issuance costs to reduce the local financial risk. It needs to establish scientific and reasonable system of credit rating and the rating agencies and emphasize the information disclosure system of local government to guarantee true and public information, so that local government's credit rating could be fairly evaluated. We could analyze the stock of local debts by using debt warning to control the risk in an acceptable range.

\section{References}

[1] Zong Liang, Zhou Zhifu. The path and the prospect of the development of local government bonds in China, International finance, 2012, (2): 60-63.

[2] Dwight V. Denison, Merl Hackbart, Michael Moody. State Debt Limits: How Many Are Enough?. Public Budgeting \& Finance, 2006 (winter):22-39.

[3] Christine R. Martell, George M. Guess. Development of Local Government Debt Financing Markets. Public Budgeting \& Finance. 2006(spring):88-119.

[4] W. Bartley Hildreth, Gerald J. Miller. Debt and the Local Economy. Public Budgeting \& Finance, 2002 (winter): 99-113.

[5] Alexander Guembel, Oren Sussman. Sovereign Debt without Default Penaltie. The review of Economic Studies, 2009, (76): 1297-1320.

[6] Wang Gang, Han Liyan. Research on risk prevention and control of municipal debts management in China, Journal of Finance and Economics, 2003, (7): 16-21.

[7] Wang Yu, Wang Hao. The research on scale of local government debt in China, Economic research guide, 2010, (31): 79-81.

[8] Cheng Zhenhuang, Wang Dongxing. The empirical research on moderate scale of our local governmental fiscal debt -- Taking Chenggong County of Kunming city as an example, Inquiry into economic issues, 2008, (7): 179-185. 